Original research article

\title{
The association of vertebrobasilar calcification with etiological subtypes, stroke recurrence and outcome in acute brainstem ischemic stroke
}

\author{
Elif Gökçal ${ }^{a, *}$, Elvin Niftaliyev ${ }^{a}$, Tuğçe Özdemir ${ }^{a, b}$, Mehmet Kolukısa ${ }^{a}$, \\ Talip Asil ${ }^{a}$ \\ a Bezmialem Vakıf University, Neurology Department, Istanbul, Turkey \\ ${ }^{\mathrm{b}}$ Mengücek Gazi Educational and Training Hospital, Erzincan, Turkey
}

\section{A R T I C L E I N F O}

Article history:

Received 5 August 2017

Accepted 27 September 2017

Available online 9 October 2017

Keywords:

Vertebrobasilar calcification, Brainstem stroke, Recurrent stroke, Outcome

\begin{abstract}
A B S T R A C T
Arterial calcification (AC), a frequent finding on imaging studies, has been reported as a risk factor for ischemic stroke. However few studies have explored the association of AC with etiological subtypes and prognostic implications. The purpose of this study was to investigate the association of AC with demograhics, risk factors and etiological subtypes and to determine whether it predicts stroke recurrence and functional outcome in patients with acute brainstem ischemic stroke. We analyzed our database consisting of patients who were diagnosed as acute brainstem ischemic stroke admitted within 24 hours of onset. Etiological classification of stroke was made based on The Trial of ORG in Acute Stroke Treatment (TOAST) Classification. AC in vertebral and basilar arteries were assessed from baseline brain CT. AC degree was categorized according to calcification along the circumference in the densest calcified segment of each vessel (0 point if no calcification in any of the CT slices, 1 point if calcification $<50 \%$ of circumference and 2 points if calcification $\geq 50 \%$ of circumference). Three AC categories were defined according to the total AC score as follows: no AC (0 point), mild AC (1-2 points), severe AC ( $\geq 3$ points). Recurrent stroke within the first 3 months of follow up and modified Rankin Score (mRS) at 3-month were reviewed. $42 \%$ of 188 patients had AC in at least of the vertebrobasilar arteries. Severe AC was related to age and the presence of diabetes mellitus and coronary artery disease. The prevalence of AC was significantly higher in large artery atherosclerosis subtype. The presence of AC was marginally associated with recurrent stroke but did not find to be related with functional outcome. Further studies with larger sample size are warranted to explore this topic.
\end{abstract}

() 2017 Polish Neurological Society. Published by Elsevier Sp. z o.o. All rights reserved.

\footnotetext{
* Corresponding author at: Bezmialem Vakıf Üniversitesi Nöroloji Kliniği, Adnan Menderes Bulvan, Fatih, İstanbul, Turkey. Tel.: +90 5054927902.

E-mail address: elifdr99@gmail.com (E. Gökçal). http://dx.doi.org/10.1016/j.pjnns.2017.09.010 0028-3843/@ 2017 Polish Neurological Society. Published by Elsevier Sp. z o.o. All rights reserved.
} 


\section{Introduction}

Arterial calcifications (AC) are frequently observed on unenhanced brain Computed Tomography (CT) and have been reported to occur in up to $90 \%$ of atherosclerotic lesions and considered as an integral part of active process of atherosclerosis [1]. There are studies reporting the presence of AC as a risk factor for ischemic stroke [2-4]. Although most of previous studies looked into carotid artery calcification, it has been suggested that distal internal carotid artery (ICA) calcification was not related with atherosclerotic plaque but with medal wall calcification [4]. The characteristics of vertebrobasilar calcification might be different from those of ICA calcification. Besides, it has been shown that detection of AC on CT may predict major clinical events including recurrent stroke and death in ischemic stroke patients [5,6]. Although vertebral artery (VA) is the second most common artery having AC [2,7], there is no study evaluating the relationship of vertebrobasilar calcification with neurological outcome in acute brainstem ischemic stroke.

In this study, we aimed to investigate the association of $\mathrm{AC}$ in VA and basilar artery (BA) with vascular risk factors and etiological subtypes and to determine whether AC predicts stroke recurrence and outcome in patients with acute brainstem ischemic stroke.

\section{Methods}

\subsection{Patients}

Between January 2012 and January 2016, we retrospectively identified patients who were admitted to our department with acute brainstem ischemic stroke. Brainstem ischemic stroke was defined as acute neurological deficit with relevant lesions on mecencephalon, pons or medulla oblongata on brain cranial Magnetic Resonance Imaging Diffusion-Weighted Images (MRI-DWI). Inclusion criteria for this study were (1) admittance to our department within 24 hours of symptom onset and (2) having brain CT imaging performed with a same 5-mm slice thickness from the skull base to the vertex.

Demographic characteristics, vascular risk factors, clinical and radiological data were collected from the patients included in the study. The following criteria were considered for vascular risk factors: a history of hypertension (HT) or an observed arterial blood pressure $>140 / 90 \mathrm{mmHg}$, presence of a history of diabetes mellitus (DM) or a fasting glucose exceeding $126 \mathrm{mg} / \mathrm{dl}$ other than that measured during the acute phase, a positive history of hyperlipidemia (HL) or a fasting total cholesterol $>200 \mathrm{mg} / \mathrm{dl}$, low density lipoprotein (LDL) >130 mg/dl, and/or a triglyceride (TG) $>180 \mathrm{mg} / \mathrm{dl}$. Data for the presence of coronary artery disease (CAD), smoking and previous history of stroke were retrieved from patients' medical records. Patients were excluded if they had significant missing data in clinical charts.

\subsection{Diagnosis and etiological classification of ischemic stroke}

Diagnostic workup included brain CT, MRI (including DWI), vascular imaging techniques (MR angiography (MRA),
Computed Tomography Angiography (CTA), or Doppler Ultrasonography of carotid and vertebral arteries), 12-lead electrocardiography (ECG) and transthoracic echocardiography (TTE). Transesophageal echocardiography (TEE) and 24hour holter ECG monitoring were performed in patients with no etiological factor and suspected of cardioembolic stroke.

Considering all variable data, etiological classification of stroke was made based on TOAST criteria [8].

\subsection{Evaluation of calcification}

A stroke physician who was blinded to clinical findings evaluated the AC on brain CT. Intracranial AC were defined as hyperdense foci with a peak density more than 90 Hounsfield units. AC degree was categorized according to calcification along the circumference in the densest calcified segment of each vessel. AC score was categorized as 0 point (no calcification in any of the CT slices), 1 point (mild calcification, calcification $<50 \%$ of circumference), and 2 points (severe calcification, $\geq 50 \%$ of circumference).

The total AC score ranged from 0 to 6 (up to 2 points per the most calcified area of both VA, and BA). Three AC categories were defined according to the total AC score as follows: no AC (0 point), mild AC (1-2 points), and severe AC ( $\geq 3$ points) $[9,10]$.

\subsection{Evaluation of recurrent stroke and outcome}

The presence of recurrent stroke in 3 month follow-up period and the modified Rankin Score (mRS) at 3-month were reviewed from database. Patients with progressive neurological deficit attributed to the index stroke in the first days of clinical presentation were not recorded as recurrent stroke. In patients with inadequate data retrieval, phone calls were made to gather information on de novo occurrence of recurrent vascular conditions and mRS evaluations.

\subsection{Statistical analysis}

SPSS (Statistical Package for Social Sciences) for Windows Version 23 software was used for statistical analyses. Mean, minimum, maximum, and percentage values were calculated for descriptive data. The Pearson chi-square test or Fischer' exact test were used to compare the differences in categorical variables. Student t-test or one-way ANOVA was used for numerical variables. Multivariate analysis were performed with multiple logistic regression to determine the independent factors ( $p<0.1$ in the univariate analysis) associated with recurrent stroke and outcome. Statistical significance was set at a $p<0.05$.

\section{Results \\ 3.1. Baseline demographics and vascular risk factors among patients}

Of 255 patients with acute brainstem infarction admitted to our department, 188 (73\%) patients fullfilled the inclusion criteria. 12 patients were excluded because of the lack of CT imaging on admission and 35 patients were excluded because 
Table 1 - Demographics and vascular risk factors in all patients and in patients without calcification (0 point), with mild (1-2 points) and with severe calcification ( $\geq 3$ points).

\begin{tabular}{lcccc} 
& $\begin{array}{c}\text { No calcification } \\
n(\%)\end{array}$ & $\begin{array}{c}\text { Mild calcification } \\
n(\%)\end{array}$ & $\begin{array}{c}\text { Severe calcification } \\
n(\%)\end{array}$ & $\begin{array}{c}\text { All patients } \\
n(\%)\end{array}$ \\
\hline Age, mean \pm SD & $61.8 \pm 12$ & $66.1 \pm 12$ & $69.1 \pm 8.4$ & $63.9 \pm 12$ \\
Sex, female & $46(41.4)$ & $20(35.7)$ & $6(28.6)$ & $72(38.3)$ \\
NIHSS, mean \pm SD & $4.77 \pm 2.54$ & $5.16 \pm 3.60$ & $4.33 \pm 1.95$ & 0.009 \\
Hypertension & $70(71.2)$ & $43(77.8)$ & $19(90.5)$ & 0.48 \\
Diabetes mellitus & $50(45)$ & $35(62.5)$ & $16(76.2)$ & $141(75)$ \\
Coronary artery disease & $22(19.8)$ & $10(17.8)$ & $11(52.4)$ & $101(53.7)$ \\
Hyperlipidemia & $45(40.5)$ & $29(51.8)$ & $9(42.9)$ & $43(22.9)$ \\
Stroke history & $28(25.2)$ & $16(28.6)$ & $3(14.3)$ & 8.48 \\
Smoking & $36(32.4)$ & $15(26.8)$ & $2(9.5)$ & 0.009 \\
\hline
\end{tabular}

Table 2 - Etiological classifications in patients with calcifications and without calcifications.

\begin{tabular}{lccc} 
Etiological classification & Calcification & Calcification & Total \\
& $n(\%)$ & $n(\%)$ & $p$ \\
\hline Large artery atherosclerosis & $25(22.9)$ & $40(50.6)$ & $65(34.6)$ \\
Cardioembolic & $16(14.7)$ & $10(12.7)$ & $26(13.8)$ \\
Small vessel disease & $48(44)$ & $23(29.1)$ & $71(37.8)$ \\
Other causes & $8(7.3)$ & $3(3.8)$ & $11(5.9)$ \\
Undetermined causes & $12(11)$ & $3(3.8)$ & $15(8)$ \\
Total & 109 & 79 & 188 \\
\hline
\end{tabular}

of significant missing data. The mean age of the patients was $63.92 \pm 12$ years (range: $23-92$ ) and the mean of The National Institutes of Health Stroke Scale (NIHSS) was $4.84 \pm 2.84$ (range: 16). There were 118 male (67.2\%), and 70 female $(32.8 \%)$. The location of the infarction was in the mesencephalon in 12 (6.3\%) patients, in pons in 119 (63.3\%) patients and in medulla oblongata in $57(30.3 \%)$ patients. $50.5 \%$ of patients exhibited infarction in the left, $48.4 \%$ exhibited in right of the brainstem and $1.1 \%$ of patients had bilateral infarction. Demographic characteristics and the incidence of risk factors are presented in Table 1.

\subsection{Etiological classification}

The etiological subtypes were classified as follows: 71 patients (37.8\%) exhibited Small Vessel Disease (SVD), 65 patients (34.6\%) exhibited Large Artery Atherosclerosis (LAA), 26 (13.8\%) exhibited Cardioembolic Etiologies (CE) and 11 patients (5.9\%) exhibited other causes. 15 patients (8\%) exhibited the undetermined etiology. The most common etiological subtypes in patients with AC were LAA and SVD. The incidence of AC was significantly higher in patients with LAA, whereas lower in patients with SVD, other causes and undetermined etiology subgroups ( $p$ : 0.002, Table 2).

\subsection{Arterial calcification}

Of all patients, 79 (42\%) had AC in at least one of the vertebrobasilar arteries. The degree of AC was mild in $29.8 \%$ and severe in $11.2 \%$ of the patients. The rate and severity of AC was lowest in the BA. The distribution of AC according to the arteries is represented in Table 3. When patients were grouped as no AC, mild AC and severe AC; the mean of age, the incidence of $\mathrm{DM}$ and $\mathrm{CAD}$ were significantly highest in patients with severe AC than in patients with mild AC and no AC groups ( $p: 0.009, p: 0.009, p: 0.003$ respectively, Table 1 ). The incidence of smoking was lowest in patients with severe AC but the difference did not reach statistical significance ( $p$ : 0.09, Table 1).

\subsection{Recurrent stroke and outcome at follow-up}

12 of all patients $(6.6 \%)$ exhibited recurrent stroke in the 3 month follow-up period. $12.7 \%$ of patients with AC, whereas $1.9 \%$ of patients without AC exhibited recurrent stroke ( $p$ : 0.004). The mean of age, NIHSS scores and the presence of HL were higher in patients having recurrent stroke ( $p$ : 0.004,

Table 3 - The incidence of arterial calcification in vertebral arteries and basilar artery.

Patients $n(\%)$

$\begin{array}{lc}\text { Right vertebral artery } & 146(77.7) \\ \text { No calcification } & 27(14.4) \\ \text { Mild calcification } & 15(8) \\ \text { Severe calcification } & \\ \text { Left vertebral artery } & 134(71.3) \\ \text { No calcification } & 33(17.6) \\ \text { Mild calcification } & 21(11.2) \\ \text { Severe calcification } & \\ \text { Basilary artery } & 155(82.4) \\ \text { No calcification } & 28(14.9) \\ \text { Mild calcification } & 5(2.7) \\ \text { Severe calcification } & \\ \text { All arteries } & 111(59) \\ \text { No calcification } & 56(29.8) \\ \text { Mild calcification } & 21(11.2) \\ \text { Severe calcification } & \end{array}$


p: $0.07, p: 0.01$ respectively). 10 of these patients had LAA and the remaining 2 patients had SVD etiological subtype.

When 130 patients with LAA and SVD etiological subtypes were analyzed, $16.4 \%$ of patients with AC whereas $2.9 \%$ of patients without AC exhibited recurrent stroke ( $p$ : 0.008). There was no statistical difference with regard to age and sex and NIHSS at onset. Among vascular risk factors, only history of stroke was found significantly higher in patients with recurrent stroke. In logistic regression analysis, the presence of recurrent stroke was found to be associated with stroke history ( $p$ : 0.01 , Odd's ratio: $0.168,95 \%$ of CI: $0.04-0.64$ ) and it was marginally associated with the presence of AC ( $p: 0.05$, Odd's ratio: 0.193 , $95 \%$ of CI: $0.03-1.04$ )

The modified Rankin Scores at 3 month were determined in 182 patients. Of these, $51(28 \%)$ had poor outcome (mRS $\geq 2$ ). Demographics, risk factors, etiological subtypes and also the presence of AC did not differ according to the functional outcome.

\section{Discussion}

In this study, we evaluated the association of AC with risk factors, etiological subtypes and investigate the effect of AC in recurrent stroke and outcome at 3-month in acute ischemic brainstem stroke.

We used unenhanced CT scans to evaluate AC because of its accessibility and being a direct method to evaluate AC. In addition, it has been reported that unenhanced CT could more readily demonstrate small amounts of calcifications and it is more sensitive for detection of calcifications when compared to CT angiography $[11,12]$.

In our study, the prevalence of AC was $42 \%$. To the best of our knowledge, there is no study reporting the prevalence of $\mathrm{AC}$ in brainstem stroke patients. In the literature evaluating all ischemic stroke patients, the prevalence of intracranial AC varies between $35 \%$ and $92 \%$ [12-15]. Contrary to our study which we focused on posterior circulation, these reported frequencies in the literature have been found by investigation of overall calcification in cerebral arteries. This wide range of prevalence in studies can be attributed to the different techniques used to detect $A C$, the differences in demographic characteristics and also ethnic differences in study populations. Indeed, there are racial differences in gene expression profiles contributing to differential risks of arterial calcification [16].

Basilar artery was the least affected artery and the prevalence of AC in left VA was slightly higher than right VA in our study, as previously reported in one study investigating the distribution of vertebrobasilar calcification in all ischemic stroke patients [17].

As in the literature, the presence and severity of AC was associated with the mean of age, presence of DM and CAD in our patients $[2,12,14,18]$. In contrary, we did not find any association of AC with HT and HL. Also in our study, the prevalence of smoking was mathematically lower in patients with AC. This should be attributed to that the patients with smoking history were significantly younger than the patients without ( $p: 0.000)$. Indeed, in logistic regression analysis, history of smoking did not correlate with the presence of AC.
Similar to the literature, the most common etiological subtype in our study population was SVD followed by LAA subtype [19]. The prevalence of AC was highest in LAA subtype in our patients. Few studies have explored the association of calcifications with specific stroke subtypes. In one study, there was no difference between lacunar and nonlacunar strokes with regard to intracranial AC in anterior circulation whereas aortic AC was more prevalent in nonlacunar strokes than in lacunar strokes in the same study [20]. In another study, intracranial internal carotid artery calcification was found to be associated with stroke of LAA and CE subtypes [12]. The authors tried to explain these findings with the possibility of the presence of internal carotid artery calcification being a reflection of more downstream events in the pathogenesis of atherosclerosis and they suggested that internal carotid artery calcification might be an imaging marker of cardiac and vascular diseases. The prevalence of CE subtype was low and also the percentage of CE etiology did not differ between patients with AC and without AC in our population. Already, most of our patients had infarction in pons and $C E$ is thought to be an unusual mechanism in pontine infarctions [21]. Several studies have reported the association of arterial calcifications with cerebral artery stenosis $[14,22,23]$. We did not explore the correlations between AC and the severity of vascular stenosis but the prevalence of AC was highest in LAA etiological subtype, which is defined as a stenosis of at least $50 \%$ lumen diameter in the relevant artery. Nevertheless, further studies are needed to explore the potential contributions of AC in different stroke subtypes.

Because recurrent stroke was observed mainly in LAA and SVD subtypes and also AC was most prevalent in these subtypes, we executed recurrent stroke analysis only in patients with these etiologies. There are studies reporting that the presence of AC is associated with major clinical events, including ischemic stroke and death in ischemic stroke patients [5,24]. The etiological subtypes were not taken in consideration in one of these aforementioned studies whereas etiological subtypes did not correlate with the presence of AC in the other study. In a recent study, the association of AC with early vascular events, including progression and recurrent stroke, was investigated and the authors reported that the presence of AC might predict early vascular events in noncardioembolic ischemic stroke patients. Contrary to our results, the prevalence of AC was lower in SVD etiological subtype in the present study. However, there was no information about the localizations of ischemic infarctions. In our results, we found a marginal association between AC and the risk of recurrent stroke. However, AC did not affect the 3-month functional outcome. Mechanisms of ischemic stroke differ in anterior and posterior circulation strokes [25].

There are limitations in our study. First, this is a retrospective study with a modest sample size. Also recurrent stroke was present in only 12 patients. This is probably because we could not enroll patients with very severe stroke and referred to Intensive Care Units from emergency department instead of our stroke service unit. Therefore, this study is vulnerable to selection bias and the results should be confirmed with larger studies. Second, we did not analyze the association of AC with vascular stenosis or hypoplasia and 
could not explore the association of AC with vascular stenosis in vertebrobasilary arteries. We did not include thalamic, occipital cortex and cerebellar infarctions having blood supply from vertebrobasilar arteries. This is because of rarity of AC in posterior cerebral arteries and other branches of vertebrobasilar system supplying cerebellum. Also brainstem ischemic stroke has a distinctive stroke mechanism with respect to other regions in posterior circulation system.

In conclusion, the degree of vertebrobasilar calcifications was associated with aging and vascular risk factors including $\mathrm{DM}$ and $\mathrm{CAD}$ and vertebrobasilar calcifications were more prevalent in LAA etiological subtype of brainstem ischemic stroke patients in our study population. We did not find any relationship with vertebrobasilar calcification and recurrent stroke, and functional outcome in brainstem ischemic stroke patients. Further studies with larger sample size are warranted to explore this topic.

\section{Conflict of interest}

None declared.

\section{Acknowledgement and financial support}

None declared.

\section{R E F E R E N C E S}

[1] Wu XH, Chen XY, Wang LJ, Wong KS. Intracranial artery calcification and its clinical significance. J Clin Neurol 2016;12 (3):253-61. http://dx.doi.org/10.3988/jen.2016.12.3.253

[2] Chen XY, Lam WW, Ng HK, Fan YH, Wong KS. The frequency and determinants of calcification in intracranial arteries in Chinese patients who underwent computed tomography examinations. Cerebrovasc Dis 2006;21(1-2):91-7. http://dx. doi.org/10.1159/000090206

[3] Bugnicourt JM, Chillon JM, Massy ZA, Canaple S, Lamy C, Deramond $\mathrm{H}$, et al. High prevalence of intracranial artery calcification in stroke patients with CKD: a retrospective study. Clin J Am Soc Nephrol 2009;4(2):284-90. http://dx.doi. org/10.2215/CJN.02140508

[4] Bos D, Portegies ML, van der Lugt A, Bos MJ, Koudstaal PJ, Hofman A, et al. Intracranial carotid artery atherosclerosis and the risk of stroke in whites: the Rotterdam Study. JAMA Neurol 2014;71(4):405-11. http://dx.doi.org/10.1001/ jamaneurol.2013.6223

[5] Bugnicourt JM, Leclercq C, Chillon JM, Diouf M, Deramond $\mathrm{H}$, Canaple S, et al. Presence of intracranial artery calcification is associated with mortality and vascular events in patients with ischemic stroke after hospital discharge a cohort study. Stroke 2011;42(12):3447-53. http:// dx.doi.org/10.1161/Strokeaha.111.618652

[6] Ovesen C, Abild A, Christensen AF, Rosenbaum S, Hansen CK, Havsteen I, et al. Prevalence and long-term clinical significance of intracranial atherosclerosis after ischaemic stroke or transient ischaemic attack: a cohort study. BMJ Open 2013;3(10). http://dx.doi.org/10.1136/bmjopen-2013$\underline{003724}$

[7] Bostrom K, Hassler O. Radiological study of arterial calcification. 2. Intracranial arteries. Neurology 1965;15 (12):1168-72.
[8] Adams Jr HP, Bendixen BH, Kappelle LJ, Biller J, Love BB, Gordon DL, et al. Classification of subtype of acute ischemic stroke. Definitions for use in a multicenter clinical trial. TOAST. Trial of Org 10172 in Acute Stroke Treatment. Stroke 1993;24(1):35-41.

[9] Koton S, Tashlykov V, Schwammenthal Y, Molshatzki N, Merzeliak O, Tsabari R, et al. Cerebral artery calcification in patients with acute cerebrovascular diseases: determinants and long-term clinical outcome. Eur J Neurol 2012;19(5): 739-45. http://dx.doi.org/10.1111/j.1468-1331.2011.03620.x

[10] Lee JG, Lee KB, Roh H, Ahn MY, Bae HJ, Lee JS, et al. Intracranial arterial calcification can predict early vascular events after acute ischemic stroke. J Stroke Cerebrovasc Dis 2014;23(5):e331-7. http://dx.doi.org/10.1016/j. jstrokecerebrovasdis.2013.12.022

[11] Ahn SS, Nam HS, Heo JH, Kim YD, Lee SK, Han K, et al. Quantification of intracranial internal carotid artery calcification on brain unenhanced CT: evaluation of its feasibility and assessment of the reliability of visual grading scales. Eur Radiol 2013;23(1):20-7. http://dx.doi.org/ 10.1007/s00330-012-2586-z

[12] Yilmaz A, Akpinar E, Topcuoglu MA, Arsava EM. Clinical and imaging features associated with intracranial internal carotid artery calcifications in patients with ischemic stroke. Neuroradiology 2015;57(5):501-6. http://dx.doi.org/ 10.1007/s00234-015-1494-8

[13] Chiewvit P, Tritrakam SO, Kraumak T. Computed tomography evaluation of intracranial vascular calcification in major ischemic stroke patients (vascular territory) - its distribution and association with vascular risk factors: a retrospective trial. J Med Assoc Thai 2015;98 (4):414-22.

[14] Sohn YH, Cheon HY, Jeon P, Kang SY. Clinical implication of cerebral artery calcification on brain CT. Cerebrovasc Dis 2004;18(4):332-7. http://dx.doi.org/10.1159/000080772

[15] Chen XY, Lam WW, Ng HK, Fan YH, Wong KS. Intracranial artery calcification: a newly identified risk factor of ischemic stroke. J Neuroimaging 2007;17(4):300-3. http://dx. doi.org/10.1111/j.1552-6569.2007.00158.x

[16] Huang CC, Lloyd-Jones DM, Guo X, Rajamannan NM, Lin S, $\mathrm{Du} \mathrm{P}$, et al. Gene expression variation between African Americans and whites is associated with coronary artery calcification: the multiethnic study of atherosclerosis. Physiol Genomics 2011;43(13):836-43. http://dx.doi.org/ 10.1152/physiolgenomics.00243.2010

[17] Pikija S, Magdic J, Hojs-Fabjan T. Calcifications of vertebrobasilar arteries on CT: detailed distribution and relation to risk factors in 245 ischemic stroke patients. Biomed Res Int 2013;918970. http://dx.doi.org/10.1155/2013/ $\underline{918970}$

[18] Mak HK, Wong CW, Yau KK, Wong WM, Gu J, Khong PL, et al. Computed tomography evaluation of intracranial atherosclerosis in Chinese patients with transient ischemic attack or minor ischemic stroke - its distribution and association with vascular risk factors. J Stroke Cerebrovasc Dis 2009;18(2):158-63. http://dx.doi.org/ 10.1016/j.jstrokecerebrovasdis.2008.09.011

[19] Lin Y, Zhang L, Bao J, Zhang B, Li H, Chen S, et al. Risk factors and etiological subtype analysis of brainstem infarctions. J Neurol Sci 2014;338(1-2):118-21. http://dx.doi. org/10.1016/j.jns.2013.12.028

[20] van Dijk AC, Fonville S, Zadi T, van Hattem AM, Saiedie G, Koudstaal PJ, et al. Association between arterial calcifications and nonlacunar and lacunar ischemic strokes. Stroke 2014;45(3):728-33. http://dx.doi.org/10.1161/ STROKEAHA.113.003197

[21] Saia V, Pantoni L. Progressive stroke in pontine infarction. Acta Neurol Scand 2009;120(4):213-5. http://dx.doi.org/ 10.1111/j.1600-0404.2009.01161.x 
[22] Woodcock Jr RJ, Goldstein JH, Kallmes DF, Cloft HJ, Phillips CD. Angiographic correlation of CT calcification in the carotid siphon. AJNR Am J Neuroradiol 1999;20(3):495-9.

[23] Kassab MY, Gupta R, Majid A, Farooq MU, Giles BP, Johnson $\mathrm{MD}$, et al. Extent of intra-arterial calcification on head CT is predictive of the degree of intracranial atherosclerosis on digital subtraction angiography. Cerebrovasc Dis 2009;28 (1):45-8. http://dx.doi.org/10.1159/000219296

[24] Ovesen C, Abild A, Christensen AF, Rosenbaum S, Hansen CK, Havsteen I, et al. Prevalence and long-term clinical significance of intracranial atherosclerosis after ischaemic stroke or transient ischaemic attack: a cohort study. BMJ Open 2013;3(10):e003724. http://dx.doi.org/10.1136/ bmjopen-2013-003724

[25] Kim JS, Nah HW, Park SM, Kim SK, Cho KH, Lee J, et al. Risk factors and stroke mechanisms in atherosclerotic stroke: intracranial compared with extracranial and anterior compared with posterior circulation disease. Stroke 2012;43(12):3313-8. http://dx.doi.org/10.1161/ STROKEAHA.112.658500 